\title{
Suitability index for restoration in landscapes: An alternative proposal for restoration projects
}

\author{
Ludmila Araujo Bortoleto ${ }^{\mathrm{a}}$, Cassio Jose Montagnani Figueira ${ }^{\mathrm{b}}$, John B. Dunning $\mathrm{Jr}^{\mathrm{c}}$, \\ John Rodgers ${ }^{\mathrm{d}}$, Alexandre Marco da Silva ${ }^{\mathrm{a}, *}$ \\ a Department of Environmental Engineering - São Paulo State University, Campus Sorocaba, 511 Três de Março Avenue, Sorocaba, SP 18087-180, Brazil \\ b Department of Environmental Sciences - Federal University of São Carlos, Campus Sorocaba, Rodovia João Leme dos Santos (SP-264), Km 110, Sorocaba, \\ SP 18052-780, Brazil \\ ${ }^{c}$ Department of Forestry and Natural Resources - Purdue University, 195 Marsteller Street, West Lafayette, IN 47907-2033, USA \\ ${ }^{\mathrm{d}}$ Department of Geosciences - Mississippi State University, 108 Hilbun Hall, Starkville, MS 39762-5448, USA
}

\section{A R T I C L E I N F O}

\section{Article history:}

Received 26 November 2014

Received in revised form 28 July 2015

Accepted 3 August 2015

Available online 31 August 2015

\section{Keywords:}

Forest fragmentation

Land cover change

Landscape connectivity

Priority areas for ecological restoration

Urban sprawl

\begin{abstract}
A B S T R A C T
Forest fragmentation constitutes one of the main consequences of land cover change worldwide. Through this process gaps in habitat coverage are created and the ability of populations in the remaining fragments to maintain themselves is put in doubt. Hence, two options need to be considered: conserving the remaining forest fragments, and restoring habitat in some deforested patches with the aim of reestablishing the connections among the fragments. We established a mathematical index (SIR) that describes the suitability of individual habitat patches for restoration within a landscape. The index considers classes of distances among fragments and categories of habitat quality in the areas surrounding the fragments to assess habitat quality in terms of probability of dispersal and survival of propagules (especially seeds and cutting). In the present study, we created detailed maps depicting SIR values for two periods (1988 and 2011) for Sorocaba region (São Paulo State, Brazil). We derived land cover maps from satellite images for the two years of our study, and then surveyed the transition of land cover categories and landscape metrics between years. A model for the SIR was created using a map of distance classes among fragments and also a map of habitat quality established according to each land cover category. For both 1988 and 2011, pasture was the predominant land cover category. The main land cover transitions were from pasture to urban (10.6\%) and from pasture to forest fragments (13.4\%). Although the land cover class "wood sites" increased, the data of SIR revealed that the areas of habitat categorized as excellent and good both decreased, while habitat classes categorized as poor and very poor increased. Our model has the potential to be applied to other regions where the forest is fragmented. Hence, local policy makers will be able to use this model to determine local patches of high value for conservation and also the most ideal locations for restoration projects.
\end{abstract}

(c) 2015 Elsevier Ltd. All rights reserved.

\section{Introduction}

Land cover is the observed (bio)physical layer on the planet's surface, describing both vegetation and man-made features (FAO, 2000). Land cover change is a spatial property observed at the scale of a landscape over time (Lambin et al., 2003; Renetzeder et al., 2010). Forest fragmentation is a process related to land cover change, in which large forest patches are broken into smaller pieces (EPA, 2003). Forest fragmentation affects both the structure and function of the landscape (Turner, 1989; Botequilha Leitão

\footnotetext{
* Corresponding author. Tel.: +55 1532383411.

E-mail address: amsilva@sorocaba.unesp.br (A.M. da Silva).
}

and Ahern, 2002). Generally, landscape structure is related to the number and spatial distribution of forest patches, while landscape functions refer to the flow of ecological processes (i.e. community dynamics, biogeochemical cycling (nutrients and water), and energy flow) among such forest fragments (Bélisle, 2005).

For landscapes already fragmented, we currently have two practical options: (a) conserving the remaining natural or semi-natural fragments, because of they are imperative for maintenance of biodiversity (Palmer et al., 2004), and/or (b) restoring portions of deforested lands, in order to generate new forested areas and, by consequence, increase the areas of remaining fragments. If placed properly, new forested areas have the role of serving as a connector between two or more fragments, which also may help populations in the remaining forest fragments. For both goals, landscape concepts and metrics should be the starting point (Ribeiro et al., 2009). 
Normally there is a scarcity of information available on the biology, ecology or the present distribution of a species, group of species, or populations, limiting our ability to analyze and model environmental degradations caused by anthropogenic activities from the perspective of individual species. Landscape ecologicalbased procedures can diminish some of these problems, because research focuses not on the organisms (animal or plant species, for example), but on the habitats and functional associations, for which data can be frequently easier to find and/or produce, e.g. land use/land cover digital maps elaborated from satellite images (Botequilha Leitão and Ahern, 2002).

The spatial patterns of a landscape are usually quantified through landscape metrics which are regarded as fundamental ecological planning tools. Landscape metrics might provide important aid for land planners and policymakers, because they can quantify the arrangement of landscape components in time and in space (Botequilha Leitão and Ahern, 2002; Herold et al., 2002; Schneiders et al., 2012; Syrbe and Walz, 2012). In the context of a fragmented forest, the area of each fragment is recognized as the main metric to be evaluated (Bell et al., 1997; Holl et al., 2003). Further, the perimeter and the ratio between area and perimeter are also of high value (Patton, 1975; Cook, 2002). The latter can be expressed by the K shape index (Schumaker, 1996) which assesses whether a given shape deviates from a perfect circle.

In terms of effects, forest patching has four mainly influence on habitat patterns: (1) reduction in habitat proportion, (2) augmentation in number of forest fragments, (3) decrease in fragment size, and (4) augment in fragment isolation, changing the habitat configuration. Habitat isolation, in particular, drives the composition and abundance of biological species. Landscapes constituted by isolated forest fragments, whether they are protected or not, have reduced biodiversity and lower species population sizes (Fahrig, 2003; Hilty et al., 2006).

Another important landscape metric is the distance among the forest fragments. When the fragments are located near each other there is usually a low level of isolation, usually providing better environmental quality in the landscape. Consequently, for forested fragments located far each other in many situations, the high level of isolation reduces the number of places with suitable environmental quality in the landscape (Fahrig, 2003). Isolation of forest fragments constitutes a filtering process dictating the kind of dispersal mechanism that might happen successfully (Hill and Curran, 2003; Kepfer-Rojas et al., 2014).

One method to quantify the degree of isolation of the fragments is analyzing the inter-patch distances among fragments. Currently, Geographic Information Systems (GIS) based models can quantify forest fragment distances and other landscape metrics from land cover imagery. However, measuring only the distance among the forest fragments results in an incomplete answer to this issue (Gurrutxaga et al., 2010).

Native vegetation fragments play a fundamental role in the resilience of human-altered areas (Alberti, 2005; Angold et al., 2006; Lopes et al., 2012). On the other hand, ecological restoration usually is a kind of service that can be complex, expensive and time-consuming (Holl et al., 2003). To mitigate the costs of landscape-related projects, GIS-based models and approaches should be used by the decision-makers, managers and other environmental-related professionals (Del Moral et al., 1991; Holl et al., 2003; Gurrutxaga et al., 2010).

It is nearly impossible to restore completely, in ecological terms, a landscape that has experienced intensive human occupation and modification, especially if the land has been used for multiple purposes. Hence, specific restoration sites should be carefully selected to maximize the ecological functions while minimizing the resource inputs (Ribeiro et al., 2009; Rudnick et al., 2012).
Policies regarding forest conservation and/or restoration often call for the establishment of corridors, which are usually linear narrow patches, and/or stepping stones that facilitate the movement of organisms between forested fragments which supports dispersal among fragmented populations and promotes genetic exchange (Chetkiewicz et al., 2006; Rudnick et al., 2012). Nonetheless, the degree to which these strategies increase connectivity may depend of how the corridors are formed and also on the composition of the surrounding matrix (Baum et al., 2004).

The land cover of the surrounding matrix defines how much a landscape resists or promotes dispersal of propagules. The quality of the matrix might be diminished by barriers and inhospitable habitats. The perception of an environment is species specific, each species will recognize it as a percolating or not (i.e., one that is more or less connected).

Some models can be used to predict when an environment that is in a state of fragmentation will begin to lose characteristics such as connectivity (Farina, 2001). Depending on the type of land cover that occurs between forest fragments, movement of organisms among fragments might be difficult. For example, if planted or commercial forests (Eucalyptus, for instance) are embedded among natural forest fragments, this would be a better scenario for dispersal than whether when urban settlements occur within natural forest fragments, even taking into account the different environmental features that each species requires to survive. However, if the analysis involves only the quality of neighboring fragments regardless of the context of distance, then an assessment of habitat quality is incomplete.

Therefore a more comprehensive technique of examining land cover fragments is needed to determine correctly the quality of the habitat existing among the forest fragments. The integration of the two features: fragment distance and quality of land cover of adjacent area of the forest fragments, might provide a cartographic product that clearly indicates gradients of landscape quality, showing areas that would require low investments for restoration and simultaneously provide high potential for adequate reestablishment of ecological conditions similar to that one verified in the fragments. Such areas would be of high interest and priority for restoration and such information would improve land management decisions (Gurrutxaga et al., 2010).

The establishment of new forested areas increases the forested area of a region and, according to the placement of the new patches, such reforested areas will also help to conserve the remaining fragments if they successfully connect each other.

In this study we assumed that (1) if forest fragmentation is directly related to land cover change, then carrying out a temporal study considering land cover change from two periods will provide an understanding of the rates and patterns of changes in this region; and (2) if forest fragmentation and isolation are directly related to distance of fragments from each other and the quality of surrounding matrix, then it is possible to establish a mathematical index that describes the potential for restoration.

Hence, the goals of the study were (1) to analyze the landscape pattern in two years: 1988 and 2011, (2) analyze landscape-related metrics for study area, and (3) present a mathematical model that permits the user to generate a map that shows the spatial variation restoration suitability, showing areas ranging from low quality of dispersal to areas with high quality of dispersal. The main usefulness of the map is to guide managers and policy makers and focus efforts and investments on restoring areas with high quality for restoration. The reasons that justify this rationale will be discussed ahead, but we highlight here that the main property that makes the model attractive is the simplicity of execution, as well as the possibility of inclusion of regional and specific data for adequate establishment of each component of the model. Furthermore, the 


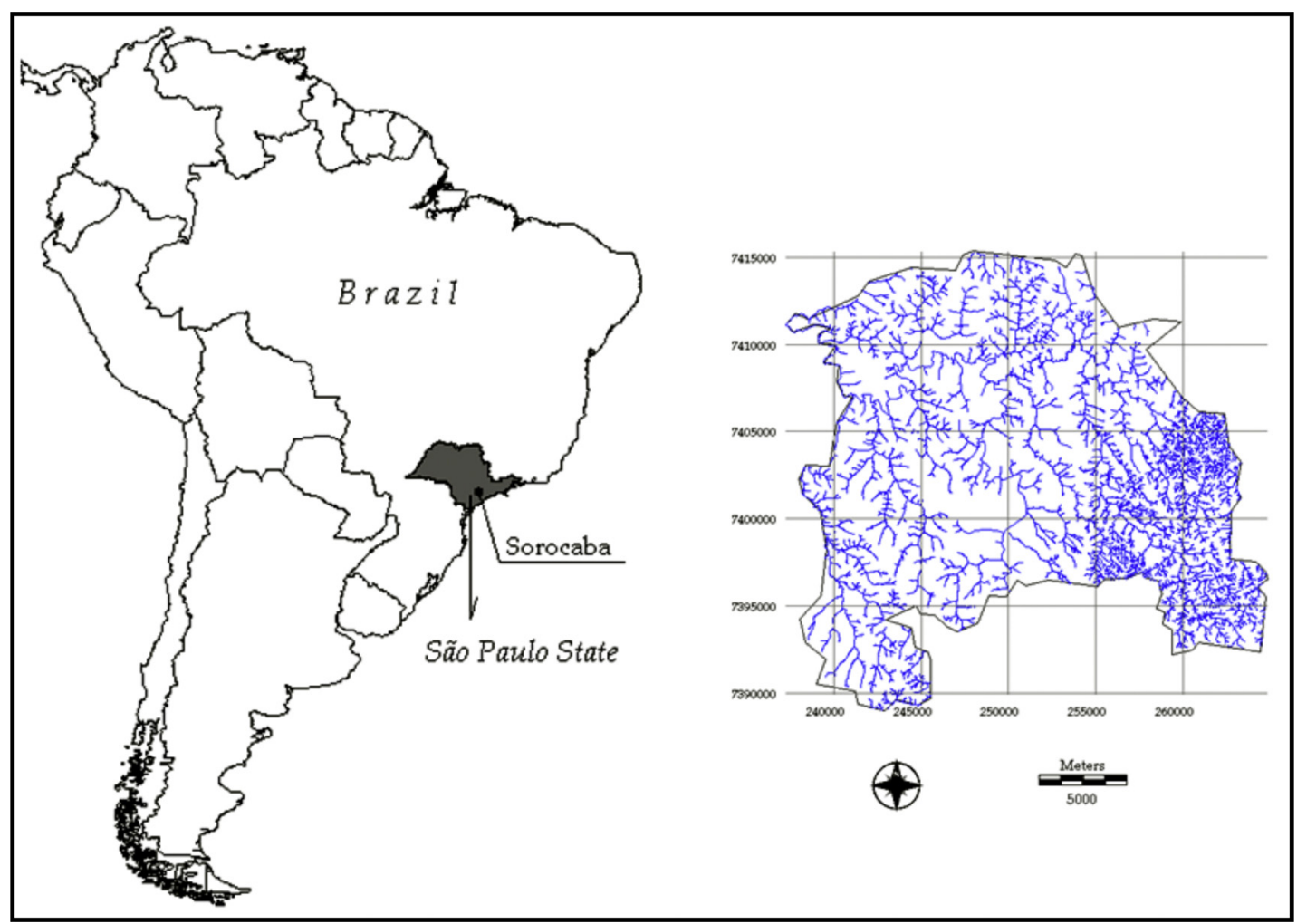

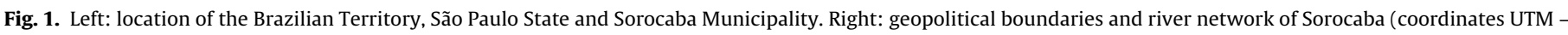
23S).

simplicity of the model permits using it in a GIS package whatever it is.

\section{Methods}

\subsection{Study site descriptions}

The area of interest for this study was the geopolitical boundary of the Sorocaba municipality, Brazilian Southeastern region (Fig. 1 - see Google Earth link). The area of the municipality is $449.8 \mathrm{~km}^{2}$ (IBGE, 2012). The climate is characterized by rainy, hot summers $\left(24.6^{\circ} \mathrm{C}\right.$ and $\left.176 \mathrm{~mm} \mathrm{month}^{-1}\right)$ and slightly cold, dry winters $\left(19.0^{\circ} \mathrm{C}\right.$ and $47.6 \mathrm{~mm}$ of rain month $\left.^{-1}\right)$. Geologically, the bedrocks are mostly fine- to medium-grained sandstones (IGSP, 2009). The main soils classes are Oxisols and Alfisols, both being deep, brown soils with very low or null stoniness, although Gleysoils and Cambsoils also occur within the region (Oliveira et al., 1999). The terrain is predominantly level or gently sloped, although in some places it is moderately or even strongly sloped (Fig. 2). There is a dense river network in the study region with at least 2332 headwaters and approximately $1199 \mathrm{~km}$ of river channels (Silveira et al., 2009). Originally, the municipality was within an ecotonal region formed by two kinds of vegetation formations: the Atlantic Rain Forest and the Brazilian Savanna (Kronka et al., 2005). Most of the vegetation, though, was removed in the last century for establishment of agriculture and mainly residential districts.

In 2012, the population of Sorocaba was estimated to be 615,955 inhabitants, with over $98 \%$ of the residents living within urban zones (SEADE, 2012). Sorocaba lies within an area where land has been exploited for at least 400 years. Especially in the last thirty years, considerable land cover changes have occurred, especially with regards to an increase in both urbanization and the road network. During the past decades in the region, shifts in landscape

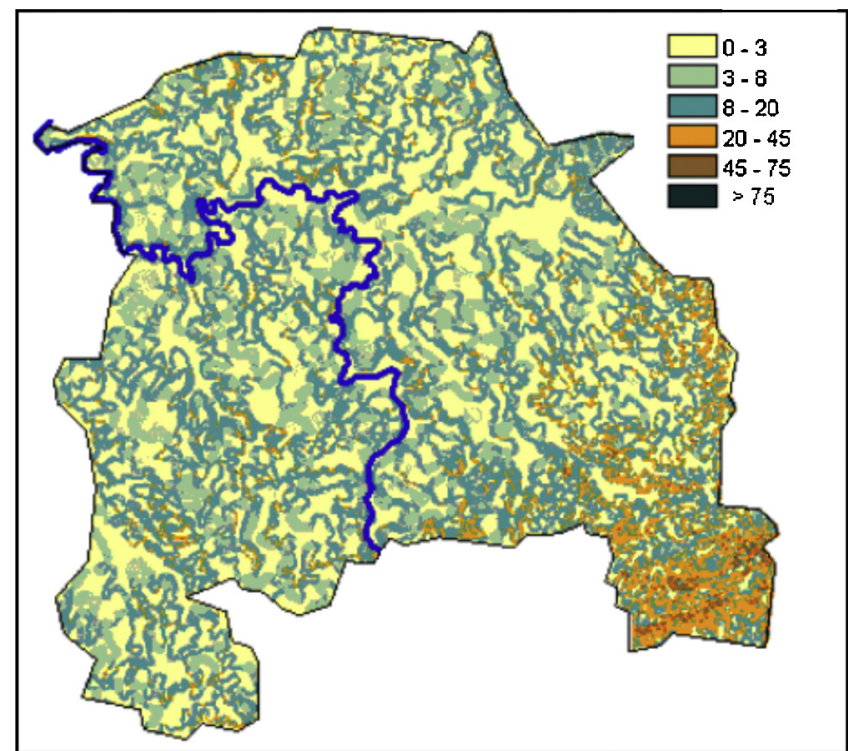

Fig. 2. Slope map for study area and river channels formed by Sorocaba River (blue line that represents the stretch of the river that passes through Sorocaba Municipality). (For interpretation of reference to color in this figure legend, the reader is referred to the web version of this article.)

Source: Modified from Silva et al. (2007).

pattern have caused a loss of ecological connectivity at the local and regional level (Smith et al., 2014).

Currently, we found hundreds of forest fragments dispersed through the study area (Bortoleto, 2014). Along with this increased urbanization, important federal and state legislations were created and implemented aiming to protect the remaining forests along the Brazilian territory and within São Paulo State, with the intended 
Table 1

Land cover categories and brief description of meaning of each class.

\begin{tabular}{ll}
\hline Land cover category & Description \\
\hline Wood sites & $\begin{array}{l}\text { Fragments of natural or planted forests in patches } \\
\text { larger than } 900 \mathrm{~m}^{2}, \text { which is the minimum area } \\
\text { detectable by the satellite sensor }\end{array}$ \\
Areas where satellite images showed the presence \\
of superficial water, either natural or artificial \\
water bodies \\
Tracts of grass-covered land \\
Pasture land & $\begin{array}{l}\text { Small-sized areas occupied with some kind of } \\
\text { agriculture mainly corn } \\
\text { Agricultural fields }\end{array}$ \\
Bare ground & $\begin{array}{l}\text { Treas densely occupied with buildings and other } \\
\text { types of structures }\end{array}$ \\
\hline
\end{tabular}

goals of minimizing forest destruction and helping the conservation of forest remnants (Rodrigues et al., 2009).

\subsection{Satellite image classification and assessment of the land cover transition}

We used two digital land cover maps classified from satellite images from 1988 and 2011 in this study (Landsat TM-5, 30 m resolution, patch/row 220/76). We chose these dates because of the availability of digital maps elaborated from Landsat satellite and because we could in field check accuracy and therefore validate the maps. Moreover, the time span of the images was important for checking important environmental modifications (as urban expansion, expansion and/or retraction of wood sites), due the economic and population development of the municipality. The land cover of 1988 was previously described in Silva (2010) and the land cover of 2011 was classified using the same procedures as in the previous study to permit comparisons (Bortoleto, 2014). The land cover classes considered for both maps are presented and explained in Table 1.

The procedures of classification were as follows. Eighty-four georeferenced points were randomly established in order to get field data and generate representative sufficient information for each land cover category of concern. In the field, for each point, the predominant land cover class occurring within a radius of $50 \mathrm{~m}$ around each point was identified and added to the digital database. This database was used to construct the signature file for a supervised classification procedure regarding each land cover class. The maximum likelihood method (Lillesand et al., 2004) was used to generate the land cover map.

After generating the first land cover map, the classification was validated via ground truth inspection (Saadat et al., 2011). For this validation, 51 new sampling points were generated following the same criteria described above and field incursions were used to verify the land cover classifications $50 \mathrm{~m}$ around each new georeferenced point. Once the new database was imported into the GIS package, the classification was validated using a Kappa index of agreement (Eastman, 2012). A value of 0.85 for the Kappa statistic is often used in the remote sensing literature as a threshold value to describe a successful classification (Lillesand et al., 2004; Silva, 2010). After several iterations, this threshold was achieved, validating the classification.

After validation, we determined the proportion of occurrence of each land cover category for both the 1998 and 2011 maps. We also cross-tabulated the maps in order to identify the sites where land cover classes changed or persisted and, for patches where land cover changed, we noted the type of change (e.g. from wood sites to agricultural fields) (Poyatos et al., 2003; Eastman, 2012).

\subsection{Landscape metrics}

The next step was the reclassification of the land cover map in order to separate the class "wood sites" from other classes (humanmade land cover classes) and generate a bimodal, Boolean map (Ries et al., 2004). In this map, the class "wood sites" received classification scores of " 1 ", and all other land cover classes received classification scores of " 0 ".

From this Boolean map, we calculated the number, area and perimeter length of forest fragments for both the 1998 and 2011 images. After computing the area and perimeter, we calculated the K shape index for each fragment (Schumaker, 1996; Cook, 2002) as:

$K=\frac{P}{2 \sqrt{\pi A}}$

where $K$ is the shape index (dimensionless); $P$ is the perimeter (meters); $A$ is the area (square meters). A $K$ value equal to 1 indicates a perfect circle, and with increasing deviations from 1 , the fragment's shape becomes less circular.

The edge effect is a heterogeneous and non-monotonic spatial phenomenon to which species and ecological functions have different responses (Rodrigues, 1998; Ries et al., 2004). Studies have shown that edge effects tend to disappear approximately $50 \mathrm{~m}$ into the core area from the fragment's edge (Murcia, 1995). Since our maps had a spatial resolution of $30 \mathrm{~m}$, we assumed that edge effects effectively occurred in the areas immediately adjacent to the patch edges. Therefore we used the bimodal map of both time periods to determine the percentage of core area for each forest fragment, calculated as all parts of the fragment that were classified as wood sites but were not immediately adjacent to non-woody edge.

\subsection{The suitability index for restoration (SIR)}

In order to show the spatial occurrence of the suitability index for restoration of a landscape, we constructed two maps (one for each period) using Eq. (2).

$\mathrm{SIR}=\mathrm{Cd} \times(\mathrm{LQ})^{2}$

where: SIR - suitability index for restoration of a landscape; Cd - classes of distance; LQ - index of local quality. All factors are dimensionless.

For each component of Eq. (2), a digital layer was required, which we derived from the land cover maps. We squared the LQ factor because we assumed that the matrix quality and surrounding landscape composition have a dominant impact on population dynamics, species diversity and ecosystem processes in forest fragments (Didham, 2010). The SIR index can be calculated using mathematical operations usually available in the cartographic segment of a GIS package.

We used the isolation metric $(\mathrm{Cd})$ to estimate the isolation of wood sites in terms of their proximity to surrounding wood sites (Hill and Curran, 2003). The isolation metric was chosen because it is one of the most commonly used metrics for evaluating interpatch distances and level of isolation. It is simply a measure of the distance between a patch and its closest neighbor (Bender et al., 2003). The level of inter-patch distance was analyzed through a map of distance classes among the forest fragments.

First, we prepared a raster-based map depicting a continuous gradient of values of distance (maps constituting a single multidirectional proximity for each wood site or forest fragment). We then made a reclassification procedure in order to generate a new map indicating the classes of distance and the associated quality according to class of distance. This new map was used in the computing of the Cd metric in Eq. (2). 
Table 2

Percentage of occurrence of each class of nearest neighbor distance between forest patches for the two studied periods.

\begin{tabular}{llrr}
\hline Intervals of distance (meters) & Interpretation & 1988 & 2011 \\
\hline $1-100$ & Very close & 24.7 & 31.0 \\
$100.1-500$ & Close & 61.3 & 60.7 \\
$500.1-1000$ & Intermediary & 11.9 & 7.0 \\
$1000.1-1500$ & Far & 1.8 & 1.1 \\
$1500.1-2000$ & Distant & 0.3 & 0.2 \\
\hline
\end{tabular}

In terms of delineating values for the distance classes, the user of the model is free to use values appropriate to the regional context and the goals of the project. In making these the classes and values, the user should consider that (a) the distance over which plants disperse seeds depends on plant traits as well as environmental conditions and varies strongly in time, space and ecosystem (Nathan, 2006); (b) a single plant species may be dispersed by multiple dispersal vectors (Nathan, 2006) and a considerable proportion of plant species have two or more dispersal modes (Vittoz and Engler, 2007); and (c) the necessity of considering multiple taxa of plant species relative to mechanisms of pollen and seed dispersion, since a natural forest is rarely formed by one single species.

Specifically of our study area, we have a region of subtropical climate and a vegetation formation of both semideciduous and savanna (i.e., an ecotonal region), where $75 \%$ of angiosperm species of the region were encountered in both formations (Koch et al., 2014). Furthermore, considering that (1) we previously verified that the inter-patch distances ranged from 30 to almost $1750 \mathrm{~m}$ in both maps, (2) considering also several aspects that might be changed considerably locally and regionally, as wind direction and speed, behavioral plasticity of the several animal species that might act as dispersal agents (mainly insects, birds and mammals), plant phenology, availability and richness of floral and fruit resources, morphological structures of pollens and seeds, and (3) considering a multi-taxa approach that we used in this project (rather than focus on one or two single species), we established five distance classes (Table 2). The distance classes were then further reclassified into a matrix of "intervals of distance" whose values ranged from 1 to 5 , where the value of 1 represented distances from 1 to $100 \mathrm{~m}$ (closest) and a value of 5 represented the longest distances.

The second variable in Eq. (2) (LQ) is regarding the quality of matrix surrounding each of the wood sites. We assume that the matrix might create mutualistic and antagonistic interactions for dispersing agents (including physical agents as the wind), as well as the influence exerted on the probability of survival of the new plant organism, as consequence of the site at which the seed is deposited (Gurrutxaga et al., 2010). Hence, according to the local land cover category, we can predict how easy or how difficult the propagules will pass through each location (in our project, a $30 \mathrm{~m} \times 30 \mathrm{~m}$ pixel) transported by the wind or by an animal or, if the seed is deposited there, how easy or difficult will be the chances for germination and survival.

The quality of the surrounding matrix varies from the ideal situation in which a dispersal agent passes freely through the matrix, to the worst situation in which a dispersal agent moves with difficulty. Clearings, agricultural fields, or other human-induced categories of land uses are likely to provide barriers to dispersal, therefore they act as filters on the landscape, allowing only some dispersers to pass (O'Neill et al., 1997). We used the land cover maps to develop an index of quality for the classes of land cover in the matrix, giving each a numeric value in which the land cover classes that are best for dispersal received the lowest values. In global terms, such values might be highly different from region to region, reflecting factors such as types of agriculture (kinds of cultivars, modalities of technology, field size, intensity and modality of agriculture
Table 3

Classification of the quality of land cover for each to land cover category.

\begin{tabular}{lll}
\hline Land cover category & $\begin{array}{l}\text { Values for the index of } \\
\text { local quality }\end{array}$ & Quality of land cover \\
\hline Wood sites & 1 & Excellent \\
Water bodies & 2 & Excellent \\
Pasture land & 3 & Good \\
Agricultural fields & 4 & Medium \\
Bare ground & 5 & Bad \\
Urban settlements & 6 & Poor \\
\hline
\end{tabular}

Scores for index of local quality modified from Schneiders et al. (2012).

(conventional or organic), as well as the types of urban settlements (residential, industrial) and location of regions (outskirt, central) among other features.

The numeric index of LQ was established for each land cover class taking into account land features and our multi taxa approach (Table 3). The term "LQ" represents the effect of a set of drivers that affect the seed transport, deposition, germination and plant growing, and also seed predation, competition with non-native vegetation, and level of soil fertility or degradation. The component "LQ" reflects how the process of natural regeneration might be favored or hampered in some altered areas. At least for vascular plants and for abandoned fields, the effect of distance is of lower influence than the quality of the matrix (Lopes et al., 2012).

After assigning the numeric value to each land cover category, we generated the map of local environmental quality by reclassifying the land cover map considering the established LQ values. Finally, we squared the values in this map and then, in sequence, multiplied these values by the map of distance classes to generate the SIR model.

The output of the SIR model ranged from excellent, for lowest numeric values $(<10)$ to very poor for highest ones $(>100)$ (Table 4$)$. Low numeric values were considered excellent because they represented both the best land cover categories for dispersal and regeneration, combined with the shortest distances among wood sites (assuming that the forest fragments are potentially source of wildlife seed and pollen dispersers, propagules, and other necessary biological products). On the other hand, the areas that present high output values were of low quality for restoration, because they consisted of land cover classes with poor local environmental quality and associated with large distances among forest fragments, considering our spatial scale of investigation ( $30 \mathrm{~m} \times 30 \mathrm{~m}$ pixel).

\section{Results}

\subsection{Land cover dynamic and landscape patterns}

Anthropogenic land cover classes, especially pastures, predominated in both periods of study. In 1988, all anthropogenic categories combined to total $80.4 \%$ of the municipality, but in 2011 this value decreased to $71.5 \%$ (Table 5). The percentage of area for urban settlements increased substantially from $10.7 \%$ in 1988 to $28.8 \%$ in 2011. Simultaneously the population in Sorocaba increased from approximately 340,000 inhabitants in 1988 to approximately 586,000 in 2011 , meaning that while the population increased $72.3 \%$, the area of urban settlement increased $169.2 \%$.

The land cover class that was chiefly altered to urban was pasture land (10.6\%). In 2011 wood vegetation was reestablished in $13.4 \%$ of the area that in 1988 was pasture. Even with these losses, the class pasture represented the highest value of persistence $(23.8 \%$ of the land that was in pasture in 1988 was still in pasture in 2011). A small percentage of wood sites were converted into urban settlement (2.0\%). The discrete and limited percentage of areas occupied by agricultural fragments corroborates the historical land use patterns of the region. 
Table 4

Results from calculation of the suitability index for restoration (SIR, dimensionless) relative to distance classes and values of Index of Local Quality.

\begin{tabular}{|c|c|c|c|c|c|}
\hline \multirow[t]{2}{*}{ Classes of gradients of distance (Cd) } & \multicolumn{5}{|c|}{ Land cover classes and values of Index of Local Quality (LQ) } \\
\hline & $\begin{array}{l}\text { Water bodies } \\
(\mathrm{LQ}=2)\end{array}$ & $\begin{array}{l}\text { Pasture land } \\
(L Q=3)\end{array}$ & $\begin{array}{l}\text { Agric. fields } \\
(\mathrm{LQ}=4)\end{array}$ & $\begin{array}{l}\text { Bare ground } \\
(L Q=5)\end{array}$ & $\begin{array}{l}\text { Urban } \\
\text { settlements } \\
(\mathrm{LQ}=6)\end{array}$ \\
\hline Very close $(\mathrm{Cd}=1)$ & 4 & 9 & 16 & 25 & 36 \\
\hline Close $(C d=2)$ & 8 & 18 & 32 & 50 & 72 \\
\hline Intermediary $(\mathrm{Cd}=3)$ & 12 & 27 & 48 & 75 & 108 \\
\hline $\operatorname{Far}(\mathrm{Cd}=4)$ & 16 & 36 & 64 & 100 & 144 \\
\hline Longest $(\mathrm{Cd}=5)$ & 20 & 45 & 80 & 125 & 180 \\
\hline
\end{tabular}

Cd - classes of distance; LQ - Index of Local Quality.

Values < 10 were classified as excellent; $11-19$ as good; 20-29 as medium, 30-99, poor; >100 - very poor.

Table 5

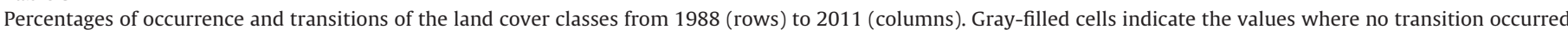
during the period of study.

\begin{tabular}{|c|c|c|c|c|c|c|c|}
\hline Land cover classes & Wood sites & Pasture & Agric f. & Urban settlements & Bare gr & Water bodies & Totals (1988) \\
\hline Wood sites & 11.9 & 4.6 & 0.7 & 2.0 & 0.5 & 0.0 & 19.6 \\
\hline Pasture land & 13.4 & 23.8 & 4.5 & 10.6 & 2.2 & 0.0 & 54.7 \\
\hline Agriculture fields & 1.1 & 0.9 & 0.3 & 0.3 & 0.1 & 0.0 & 2.7 \\
\hline Urban settlements & 0.5 & 0.6 & 0.1 & 9.2 & 0.2 & 0.0 & 10.7 \\
\hline Bare ground & 1.3 & 2.6 & 0.8 & 6.6 & 0.6 & 0.0 & 11.8 \\
\hline Water bodies & 0.3 & 0.1 & 0.0 & 0.1 & 0.0 & 0.1 & 0.6 \\
\hline Totals (2011) & 28.5 & 32.5 & 6.4 & 28.8 & 3.6 & 0.2 & 100.0 \\
\hline
\end{tabular}

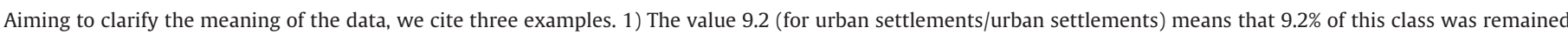

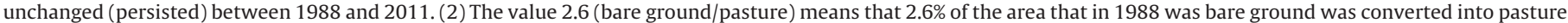
in 2011. (3) The value 2.2 (pasture/bare ground) means that $2.2 \%$ of the area that in 1988 was pasture was converted into bare ground in 2011.

Land cover classes also changed during the studied period in more subtle ways (Table 5). For example, of the area occupied by wood sites in 1988 , approximately $10 \%$ was converted into urban settlement (compared to $2.0 \%$ of wood sites converted to urban settlements), signifying that urbanization occurred on almost a quarter of the total deforested area that had been converted into pasture and approximately $6.0 \%$ that had been converted into agriculture or bare ground.

Although we note the emergence and increasing of some urban patches throughout the study area, it is evident that the main form of urban sprawl occurred as expanding rings that originated from the main, oldest urban patch that existed in 1988 (Fig. 3). This can be seen in the region where the coordinates 250,000 $\mathrm{m}$ Easting and
$7400,000 \mathrm{~m}$ Northing cross, considering this as a reference point in both maps.

The configuration of the relief and the river network are important limiting features that explain this tendency for urbanization to the north and west, because in these regions there were more suitable areas for urban expansion. In contrast, expansion in the southern region was tightly restricted by barriers created from the geopolitical limits of a neighboring municipality (Votorantim). Expansion in the eastern portion of the region was precluded due to the uneven terrain and presence of a dense river network.

Wood sites were indiscriminately scattered throughout the study area during both time periods. From the $128.2 \mathrm{~km}^{2}$ of wood sites in 2011 ( $28.5 \%$ of the whole area), $53.5 \mathrm{~km}^{2}$ were wood sites
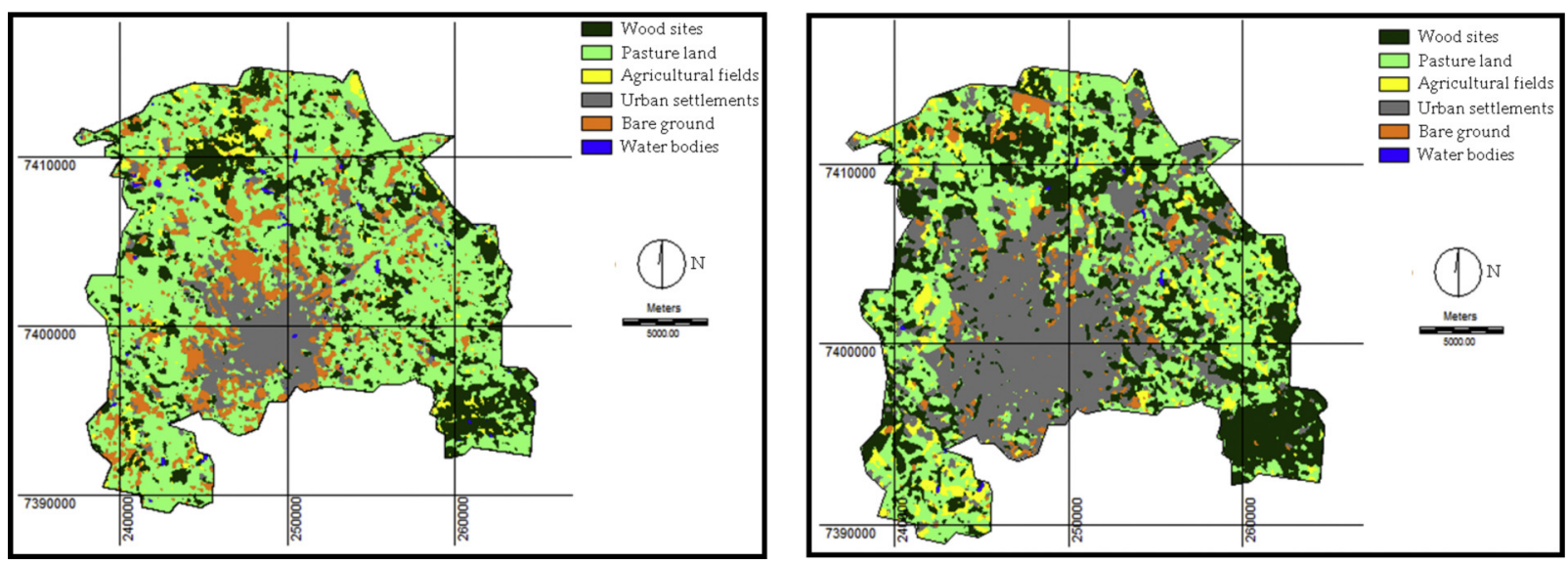

Fig. 3. Land cover maps of Sorocaba area from Landsat-5 satellite image for 1988 (left) and 2011 (right). Geographic coordinates in UTM system (zone 23S). 


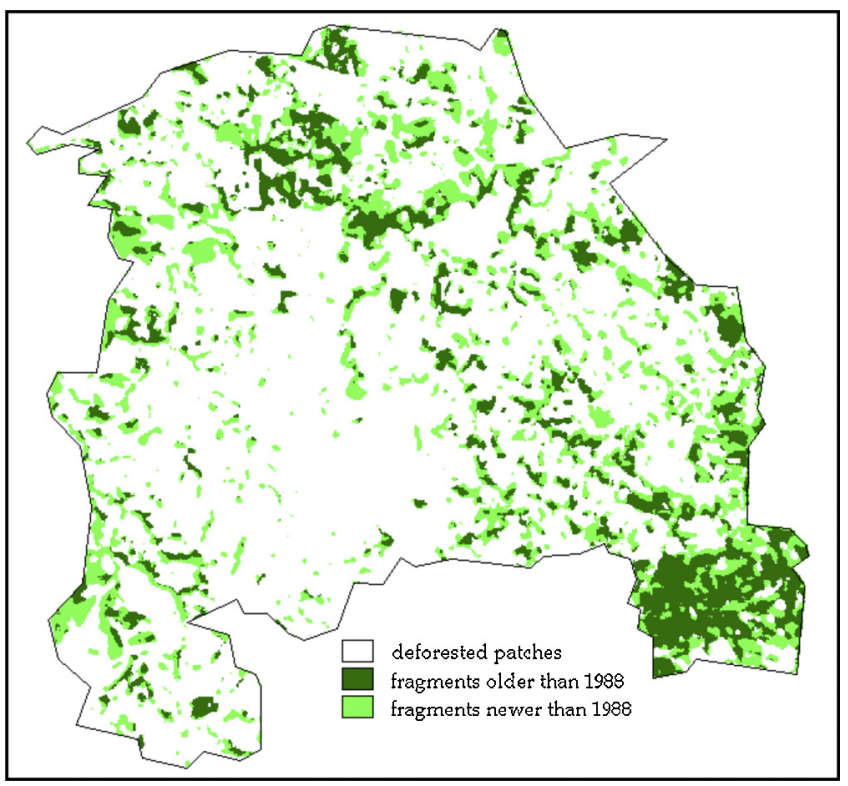

Fig. 4. Forest fragments existing in 2011. Dark green areas indicate fragments that existed as forest in 1988, light green areas are forests newer than 1988. (For interpretation of reference to color in this figure legend, the reader is referred to the web version of this article.)

that previously existed in 1988 . Thus, $16.6 \%$ of the category wood sites during 2011 correspond to new forested ecosystems that were reestablished either naturally or intentionally. Although the wood sites continued to be scattered throughout the studied area over time, we noted the formation of more connected forested regions in 2011 than in 1988 (Fig. 4).

Most fragments were $<100$ ha in both periods ( $98.3 \%$ of all fragments in 1988 and $97.6 \%$ in 2011), and an important fraction of the fragments were $<1$ ha (Table 6 ). However, when the two periods are compared, a noticeable decrease in the number of fragments of the first two size classes was observed.

It is evident that an important connection occurred among some specific fragments (Fig. 5). In particular, there were fragments that jointly formed the second largest fragment in terms of area (area $>1000$ ha, depicted in the map of 2011 - see right map of Fig. 5). This notable corridor is in the riparian zone of the Pirajibu River, the most important tributary of Sorocaba River that is located in the inner region of the study area.

Moreover, both the mean area of forest fragments and the mean value for fragment perimeter also nearly doubled between 1988 and 2011 (Table 7). However, such variation was not reflected in the $\mathrm{K}$ shape index, because discrete differences of $\mathrm{K}$ shape index did not occur among the two time periods.

In 2011, forest fragments were slightly less circular than in 1988 , but the differences in circularity were not appreciably different. The average percentage of the core area in the fragments increased approximately $7 \%$, suggesting that the fragments became less vulnerable to external influences, i.e., less vulnerable to edge effects. Complementarily, in 1988, 397 forest fragments (51\%) had no core area due to their small size and shape, while in 2011 this number was reduced to 226 (37\%).

\subsection{Suitability index for restoration (SIR) - components of the model and the final results}

We also examined the average value of inter-patch distances among the fragments for the two periods. For both periods, the most common distance between nearest forest fragments was between 100 and $500 \mathrm{~m}$ (see Table 2). The second most common distance during both periods was composed of distances $<100 \mathrm{~m}$. The longest inter-patch distances observed were 1736 and $1747 \mathrm{~m}$, for 1988 and 2011, respectively. The most common classes of distances were largely created by the large urbanized region of Sorocaba, especially in 2011 (Fig. 6).

Wood sites were ranked in the class excellent under the index of local quality (LQ Fig. 7), indicating that these habitat areas were of high value for conservation. In both maps, the south-central region had high concentrations of areas ranked with the worst LQ values. The same pattern (poor quality habitat in the south-central) was also evident in the maps depicting areas with potential for restoration (Fig. 8). The central region of the city was the area with the worst suitability for restoration and this area of concentration greatly expanded in 2011 when compared with 1988.

Regarding the category water bodies, we classified areas in this land cover category as excellent (value 2 , see Table 3 ). For our study area water bodies were typically small in size and they sometimes dried out during the year. Thus water bodies in our study region were areas where seeds might germinate or (if the water was deep) they might be spread by movement of the water (because water can be a secondary mechanism of dispersion, Shivanna and Tandon, 2014). However, a user in other part of the world might interpret this land cover category differently and assign other (eventually worse) index value.

The percentage of 'excellent' areas remained virtually unchanged during the 23-year period. On the other hand, areas ranked as medium quality were predominant in 1988 but were noticeably reduced in 2011 (from $45.7 \%$ to $28.2 \%$ ). Areas considered of poor quality almost doubled in percentage between the two periods and became the predominant class in 2011. Comparing
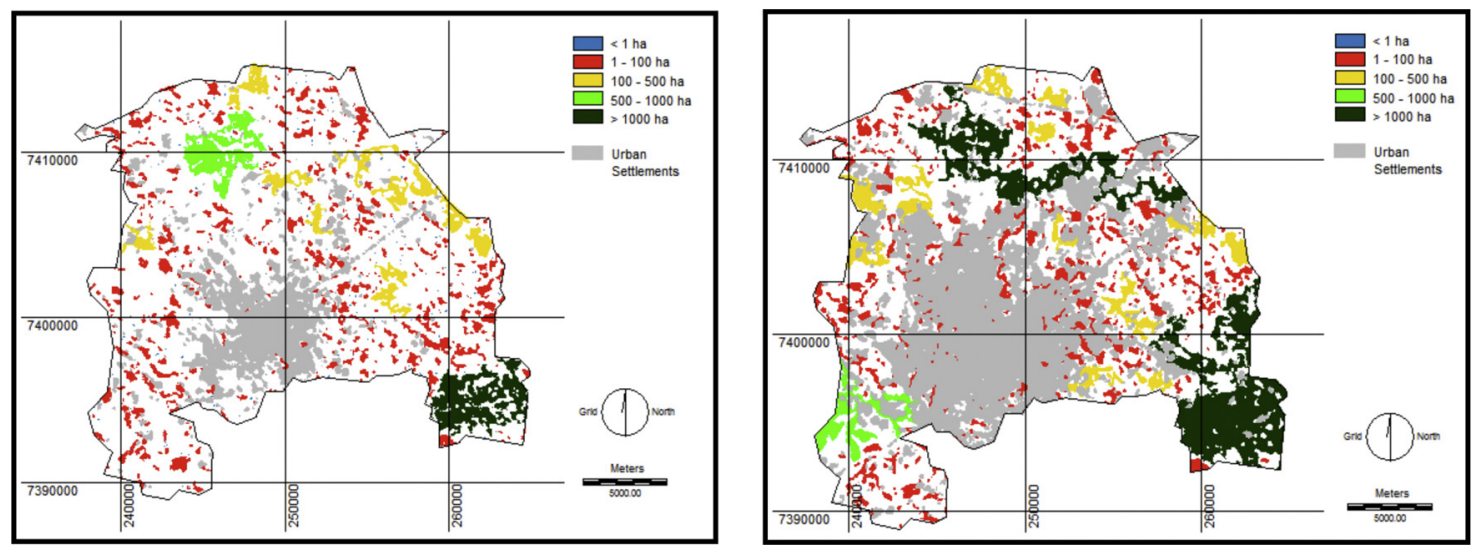

Fig. 5. Distribution of the forest fragments and their respective class of size. Left: map for 1988. Right: map for 2011. 
Table 6

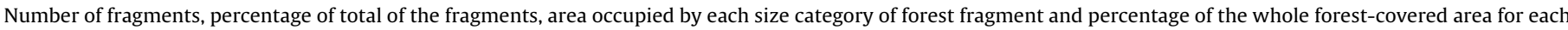
size interval for 1988 and 2011.

\begin{tabular}{|c|c|c|c|c|c|c|c|c|}
\hline \multirow[t]{2}{*}{ Size (ha) } & \multicolumn{4}{|l|}{1988} & \multicolumn{4}{|l|}{2011} \\
\hline & $\begin{array}{l}\text { Number of } \\
\text { fragments }\end{array}$ & $\begin{array}{l}\text { Percentage of total of } \\
\text { the fragments }\end{array}$ & Area (ha) & $\begin{array}{l}\text { Percentage of the } \\
\text { whole forest-covered } \\
\text { area }\end{array}$ & $\begin{array}{l}\text { Number of } \\
\text { fragments }\end{array}$ & $\begin{array}{l}\text { Percentage of total of } \\
\text { the fragments }\end{array}$ & Area (ha) & $\begin{array}{l}\text { Percentage of the } \\
\text { whole forest-covered } \\
\text { area }\end{array}$ \\
\hline$<1$ & 367 & 47.2 & 112.3 & 1.3 & 219 & 35.6 & 76.1 & 0.6 \\
\hline $1-100$ & 397 & 51.1 & 4445.0 & 50.7 & 382 & 62.0 & 4610.5 & 35.9 \\
\hline $100.1-500$ & 11 & 1.4 & 1835.8 & 20.9 & 12 & 1.9 & 2183.6 & 17.0 \\
\hline $500.1-1000$ & 1 & 0.1 & 989.4 & 11.3 & 1 & 0.2 & 722.1 & 5.6 \\
\hline$>1000$ & 1 & 0.1 & 1389.7 & 15.8 & 2 & 0.3 & 5234.6 & 40.8 \\
\hline Totals & 777 & 100.0 & 8772.2 & 100.0 & 616 & 100.0 & $12,826.9$ & 100.0 \\
\hline
\end{tabular}

Table 7

Forest fragments metrics for the two periods of study.

\begin{tabular}{|c|c|c|c|}
\hline Forest fragments metrics, definition and units & Descriptors & 1988 & 2011 \\
\hline Area, ha & $\begin{array}{l}\text { Minimum } \\
\text { Maximum } \\
\text { Average } \\
\text { Coefficient of variation (\%) }\end{array}$ & $\begin{array}{r}0.09 \\
1387.8 \\
9.5 \\
602.6\end{array}$ & $\begin{array}{r}0.09 \\
2990.34 \\
19.4 \\
754.4\end{array}$ \\
\hline Perimeter, $\mathrm{m}$ & $\begin{array}{l}\text { Minimum } \\
\text { Maximum } \\
\text { Average } \\
\text { Coefficient of variation (\%) }\end{array}$ & $\begin{array}{r}120 \\
100,800 \\
1372 \\
321.1\end{array}$ & $\begin{array}{r}120 \\
153,300 \\
2111 \\
426.9\end{array}$ \\
\hline $\begin{array}{l}\text { K shape index, } \\
\text { dimensionless }\end{array}$ & $\begin{array}{l}\text { Minimum } \\
\text { Maximum } \\
\text { Average } \\
\text { Coefficient of variation (\%) }\end{array}$ & $\begin{array}{c}1.13 \\
7.63 \\
1.51 \\
32.9\end{array}$ & $\begin{array}{c}1.13 \\
9.49 \\
1.58 \\
41.6\end{array}$ \\
\hline $\begin{array}{l}\% \text { of core area-corresponds to the percentage of the } \\
\text { forest fragment, within } 30 \text { meters depth-of-edge of the } \\
\text { fragment, free of some environmental pressure, } \\
\text { especially human induced (Gustafson, 1998) }\end{array}$ & $\begin{array}{l}\text { Minimum } \\
\text { Maximum } \\
\text { Average } \\
\text { Coefficient of variation (\%) }\end{array}$ & $\begin{array}{r}0.0 \\
89.0 \\
26.0 \\
109.4\end{array}$ & $\begin{array}{r}0.0 \\
89.3 \\
32.8 \\
88.8\end{array}$ \\
\hline
\end{tabular}

the two periods, in 1988 fragments were more distant from each other and the urban settlement occurred in minor percentage. Due to the wide expansion of the urbanized area, in 2011 although several fragments were closer each other, the quality of the matrix became worse for several fragments.

For our study area, the SIR index ranged from the best situation (class excellent), with a score of 4 , to the poorest class with a score of 180 (see Table 4). Highest quality values for the SIR index occurred near river networks and near patches within the pasture or agricultural fields land cover classes. On the other hand, the worst SIR values occurred where forest fragments were interspersed among urban settlements and, at same time, where the forest fragments were considerably distant from each other.

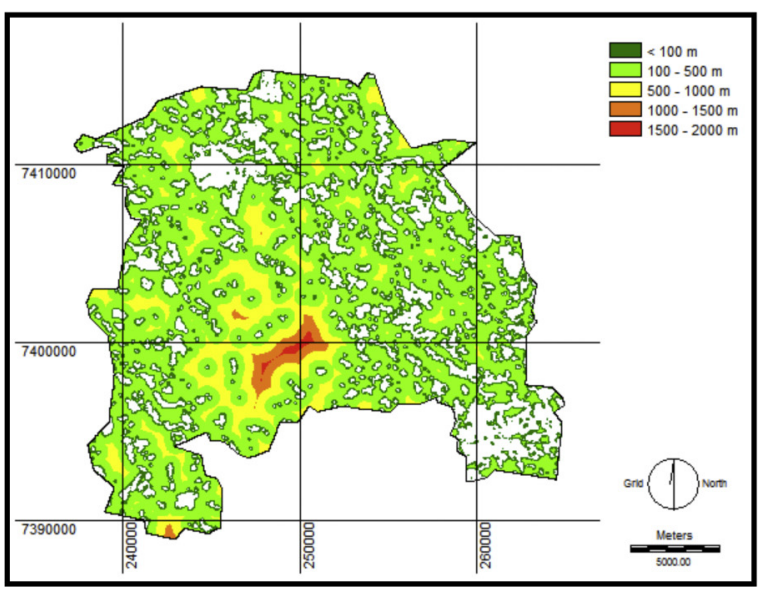

Comparing the SIR values and maps between the two periods (Fig. 8) we can see that the areas classified as "excellent' declined only slightly from 1988 to 2011 . The 'good' and 'medium' SIR values, though, decreased in area by over $38 \%$. Areas classified as 'poor' increased by $96 \%$ from 1988 to 2011 . However areas classified as 'very poor' remained relatively constant during that same time period (Table 8).

\section{Discussion}

\subsection{Land cover dynamic and landscape patterns}

Forest fragmentation might occur naturally or by human interference (Hilty et al., 2006). Rivers, streams and wetlands are among

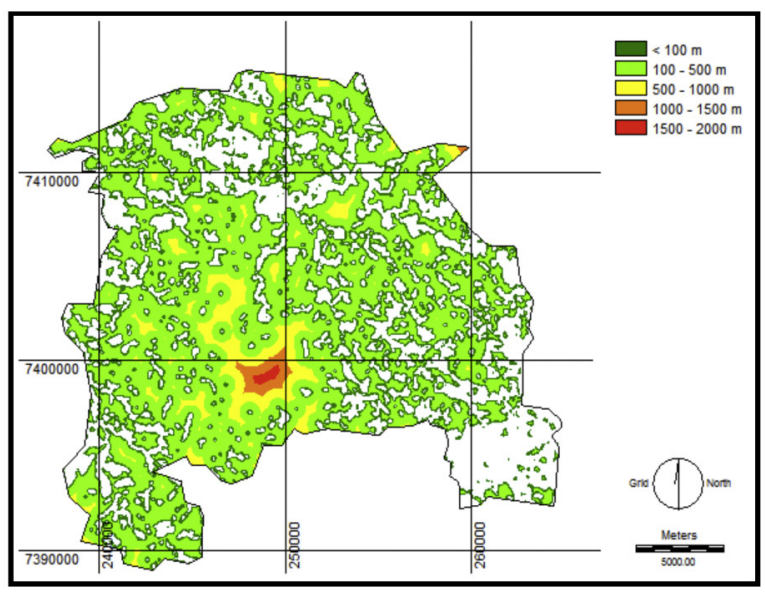

Fig. 6. Distance gradient classes among the forest fragments for 1988 (left) and for 2011 (right). 

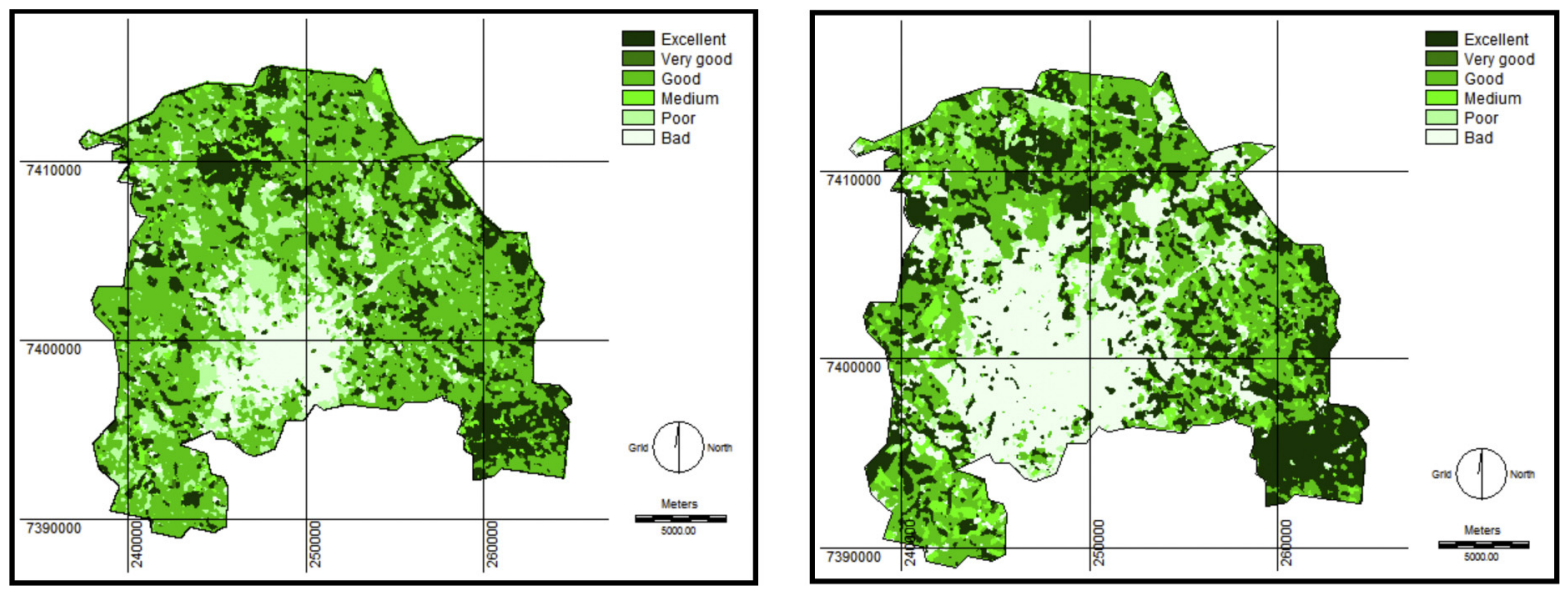

Fig. 7. Distribution of the index of local quality classes in Sorocaba for 1988 (left) and for 2011 (right).
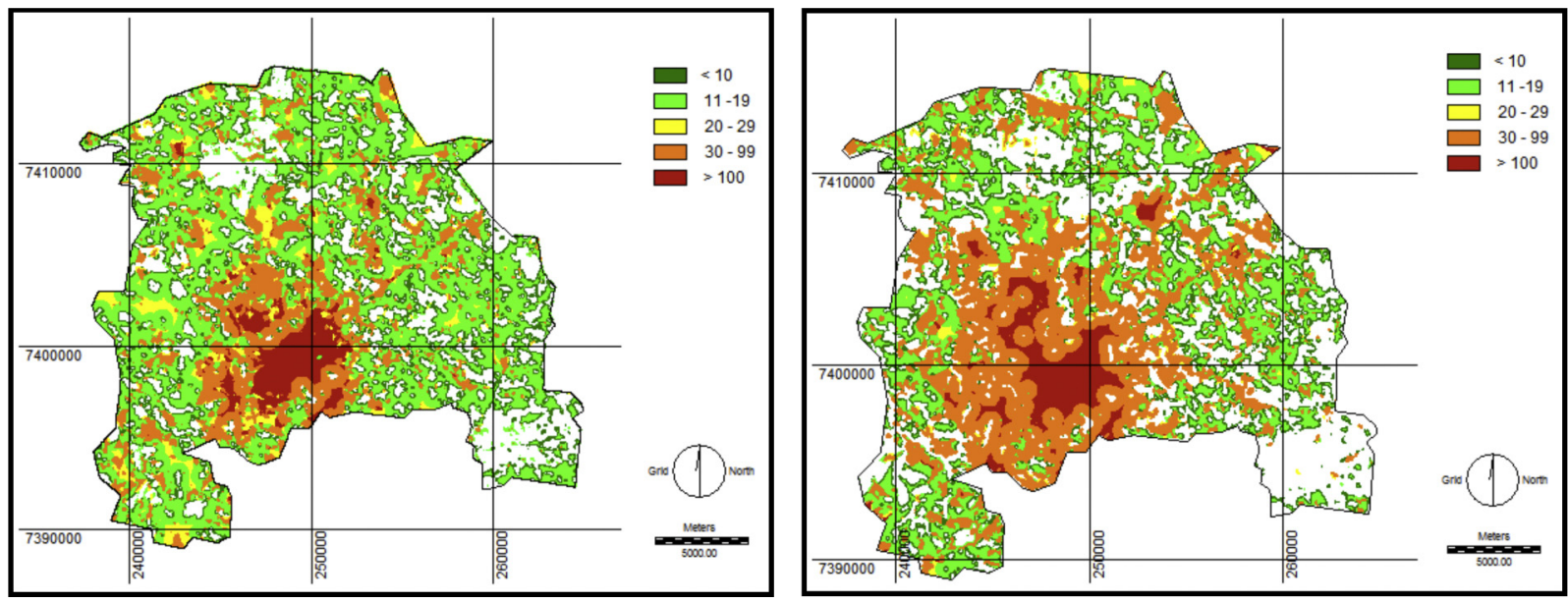

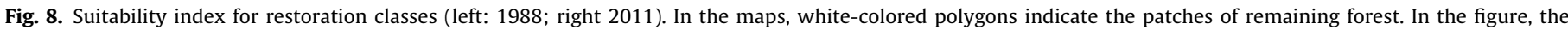
classification is: <10: excellent; 11-19: good; 20-29: medium; 30-99: poor; >100: very poor.

Table 8

Percentage of occurrences of each class suitability index for restoration (SIR) for the two studied periods.

\begin{tabular}{lrr}
\hline Intervals for values of SIR & 1988 & 2011 \\
\hline$<10$ (excellent) & 20.0 & 19.1 \\
$11-19$ (good) & 45.7 & 28.2 \\
$20-29$ (medium) & 6.4 & 2.4 \\
$30-99$ (poor) & 22.1 & 43.4 \\
$>100$ (very poor) & 5.8 & 7.0 \\
Totals & 100.0 & 100.0 \\
\hline
\end{tabular}

the most common factors responsible for naturally induced fragmentation (EPA, 2003). For the case of Sorocaba, although the regional river network is dense and rich (Silveira et al., 2009), the fragmentation process was induced primarily by anthropogenic activities, following the regional trends of the São Paulo State (Durigan et al., 2003; Ribeiro et al., 2009).

In $45 \%$ of total studied area, the land cover remained unchanged from 1988 to 2011 (see the sum of all gray-filled cells of Table 5). For example, of the wood sites, the $11.9 \%$ persisting in 2011 signifies that $61 \%$ of wood sites in 1988 did not change during our study period. Such areas contain high values of local biodiversity, both intra-specific (as sources of genetic conservation) and inter-specific, and should be considered as high priorities for conservation. Although some human uses are compatible with conservation in forest patches like these (selective logging, for example, Gibson et al., 2011), in our study area we recommend that such activities should not be practiced. The predominance of small-sized fragments suggests that the best option is conservation.

Our data showed that in Sorocaba the land use became more efficient since 1988. In other words, in 1988 we detected large areas grass-covered, but those areas were not used for livestock grazing or any other economic activity. Hence we considered these areas practically abandoned. From 1988 to 2011, several of these areas changed into one of the two main non-pasture categories of land cover: wood sites or urbanization, permitting the re-establishment of wildlife (in the case of wood sites) or human settlements (in the case of urbanization). This efficiency of land-use trends identified in Sorocaba is similar to the trends reported by Lapola et al. (2014) for other Brazilian territories.

However, such efficiency in land use has only slightly improved the region's environmental quality in terms of forest connectivity. The low predominance of large fragments identified in this study was also reported in other Brazilian regions. For example, along the Atlantic Rain Forest, Ribeiro et al. (2009) reported that more than $80 \%$ of the fragments are smaller than 50 ha and that the fragments average $1440 \mathrm{~m}$ from each other. In the Brazilian Northeastern region (State of Pernambuco), Ranta et al. (1998) reported that only $7 \%$ of the fragments were larger than 100 ha in a region containing 1839 forest fragments, many of which were surrounded mainly by fields of sugar-cane. 
The category of land cover that was most common in the landscape matrix of Sorocaba was the pasture. This is similar to landscapes in the middle and western regions of São Paulo State, regardless the regional level of urbanization (Silva et al., 2007). Pasture is a kind of ground cover that, although in several occasions permit the occurrence of the invasion of exotic plant species, also has potential to be colonized by propagules of native species coming from adjacent forest fragments. This helps to explain the relatively high percentage of conversion from pasture in 1988 to wood sites in 2011.

Urbanization is an important feature for Sorocaba, reflecting the historical roots of the municipality in industry, and the fact that a substantial part of the current population lives in urban neighborhoods. The expansion of the urbanized portion of the region is an important concern, because this is now a primary anthropogenic originator of forest fragmentation (Gong et al., 2013).

Urban development tends to reduce, isolate, and degrade pristine, forested habitats resulting in simplification and homogenization of species composition, damage to hydrological systems, and alterations in energy flow and nutrient cycling (Alberti, 2005). The reestablishment of ecological attributes of fragmented landscapes, especially in the landscape matrix, is a difficult process and the comprehension and prediction of the trajectories of this new environment requires a global and long-term observation in terms of the structure and functioning of the ecosystem in question. The increased urban sprawl observed in Sorocaba is mostly due to rural migration of the people to urban settlements, including migration of people from adjacent municipalities. Sorocaba has a large number of industries and from 1992 to 2012 the number of positions in the industry increased approximately $130 \%$ (FIESP, 2013).

In addition to the slow improvement of forest connectivity earlier mentioned, we detected a slight diminution in the number of the fragments smaller than 1 ha. Three possibilities might be the cause of this decrease in small patches: (a) the elimination of some of the fragments, (b) increase in area of some of them, or (c) the connection of one small fragment with other(s), resulting in a new bigger one. In 1988, 50.7\% of the total wood area was represented by fragments with sizes ranging from 1 to 100 ha. Fragments larger than 500 ha represented approximately one quarter of the total area. In 2011 such large fragments represented almost a half of the total wood-covered area of Sorocaba.

The mean value of the K shape index remained almost identical for the two considered periods. The mean value in both years of our study was about 1.5 , suggesting that many patches were close to circular (represented by a K shape index of 1.0) with low edge effects. The $\mathrm{K}$ shape indices were quite variable in both years (CV $32.9,1988 ; 41,2011$; Table 7), indicating elongated or rectangular fragment shapes that would have higher edge effects and less protected core habitat (Ewers and Didham, 2007).

\subsection{Suitability index for restoration (SIR) and implications in projects of restoration}

In terms of practical implications, our final outcome from the 2011 analysis indicated that some non-wood sites in the eastern region of the study area were classified as 'excellent' or 'good' suitability for restoration. The maps of Fig. 8 show that many sites where the SIR was classified as excellent or good, fell between two or more wood areas, and in practice, such patches should receive high priority in restoration projects, because they are patches where a low amount of investment could have the potential to provide a satisfactory ecological performance or high probability of success in terms of forest species recolonization.

In the areas classified as excellent, we propose that the simple abandonment of the area, meaning stopping any kind of human pressure (Hobbs and Cramer, 2008), may be enough to allow the recolonization. The proximity of these areas to forest fragments favors the deposition of seeds, regardless of kind of dispersion (via wind or animal). At the same time, the land cover of these areas favors the germination of seeds and successful growth of new plants. This means that in a few years, the closest remaining fragments located near the areas classified as excellent would be better connected (at least structurally) to each other, stimulating the potential for self-recovery (Rodrigues et al., 2009).

Moreover, another important ecological benefit implicit in this proposal is the genetic similarity of the plant community. Since the reforestation will proceed from local sources of new plants, the new restored plant community will contain a genetic constitution that is well adapted to the regional environmental features (climate, relief, soil).

Based on this proposal, we believe that small scale restoration projects (areas of $1 \mathrm{~km}^{2}$ or smaller) could be favored. However, small-scale projects should constitute parts of a large-scale (regional) plan, because large ecological restoration activities have better potential to generate more publicity than restoration of small fragments or patches and thus be protected from future impacts because of increased public awareness (Cairns and Heckman, 1996).

We propose that restoration proposals that are technically sound (science-based) are also socially robust (i.e., relatively easy to obtain collaboration of local population) and more feasible to decision makers. One justification is, for example, the fact that the invasion of exotic species in abandoned lands or fragmented forest landscapes is inevitable, especially in pasture lands (Florentine and Westbrooke, 2004). Pasture land is an important land cover category for our study area and for most parts of the São Paulo State, and invasive grass is a common critical problem.

Hence, cheap complementary services might be considered. An alternative is the cultivation of pumpkin, zucchini or other crops of economic importance that cover the ground surface, in order to control the spread of exotic grasses (César et al., 2013). In addition, these species produce flowers and fruits that might be attractive to pollinator insects and/or mammals that also act as seed-dispersers. Such approach is important because the invader grass has a rapid growth rate and usually covers the soil successfully. On the other hand, although the grass covers the ground surface and therefore provides a benefit in terms of soil conservation; at some point this exotic vegetation will need to be replaced by other species that also have the potential to cover the ground, but can control invasive species and permit the establishment of the new young trees.

Linear strips of habitat that aid the movement of organisms throughout landscapes are currently cornerstones of modern conservation. Although they are not a unique solution to conservation-related problems, corridors are one of the more important landscape arrangements capable of maintaining or restoring the patterns of species diversity (Chetkiewicz et al., 2006). However, our proposal is not just to establish corridors, but truly link areas, as also stated by Gurrutxaga et al. (2010), that might require other kinds of connectors instead of just linear strips.

Under the classic forms of creation and management of environmentally protected areas, the government usually takes the responsibility for establishing and managing such lands, as parks or reserves. Similarly, we envision a system where government purchases and manages lands aimed at increasing the connectivity of fragments (Lausche et al., 2013). For example, protecting the remaining forest fragments as critical areas for conservation should be a mandatory starting point to the success of restoration projects following the considerations here stated. Since the government cannot be the owner of all lands destined to conservation, it should be a partner and encourage the development of attitudes in favor of conservation of the fragments. The map protocol as developed here would be of high value for selecting suitable areas for 
restoration and establishment of potential partners to collaborate in this project.

\section{Conclusion and final remarks}

Our data showed that in our study area, urban settlement substantially expanded during the study period. On the other hand, the area of wood vegetation also expanded. However, pasture was the main land cover category for both periods, as it was the land cover category that was changed most notably, but also persisted to the greatest extent.

During the study period there was an increase in wood area cover, but the number of fragments diminished, because the mean area of the individual forest fragments increased. A slightly higher percentage of the fragments (average value) became less exposed to edge effects due the small increase in average core area (from $26.0 \%$ in 1988 to $32.8 \%$ in 2011 ).

The suitability index for restoration revealed that the areas of habitat ranked both excellent and good decreased, while the habitat ranked poor and very poor increased. This is mainly due the huge expansion of the urban settlements. This is an issue that land managers will need to consider in order to improve forest restoration and to better ensure local biodiversity. We highlight that this situation was best perceived through the use of the proposed model, as it was difficult to determine just analyzing the land cover map, even with GIS technology.

Our final and main result is an attempt to help solving this problem, permitting selection of places for restoration. We suggest that the model is easy and feasible to be used by policy makers when the goal is identifying suitable and strategic places for ecological restoration. This will help avoid the misuse of financial resources and also avoid wasted time with unsuccessful projects. Our model is also flexible in terms of establishment of classes of distances, as well as classes regarding the index of local quality, meaning that users, anywhere they are, may use of their own data (of distance and of land cover quality) according to the regional scenario where the project will carried out.

For our study place, at the local scale the SIR of 2011 should allow decision makers to detect in detail the best places to restore forest fragments and to recover the environmental conditions and to help improve the quality of organism movement and dispersal on a more generalized scale.

\section{Acknowledgements}

We thank to Brazilian National Institute for Spatial Researches for providing the satellite image of 2011. We also thank UNESP for allowing the use of computers with licensed versions of the GIS packages used in this project.

\section{Appendix A. Supplementary data}

Supplementary data associated with this article can be found, in the online version, at http://dx.doi.org/10.1016/j.ecolind.2015.08. 002. These data include Google maps of the most important areas described in this article.

\section{References}

Alberti, M., 2005. The effects of urban patterns on ecosystem function. Int. Reg. Sci. Rev. 28, 168-192.

Angold, P.G., Sadler, J.P., Hill, M.O., Pullin, A., Rushton, S., Austin, K., Thompson, K., 2006. Biodiversity in urban habitat patches. Sci. Total Environ. 360, 196-204.

Baum, K.A., Haynes, K.J., Dillemuth, F.P., Cronin, J.T., 2004. The matrix enhances the effectiveness of corridors and stepping stones. Ecology 85 (10), 2671-2676.

Bélisle, M., 2005. Measuring landscape connectivity: the challenge of behavioral landscape ecology. Ecology 86 (8), 1988-1995.
Bell, S.S., Fonseca, M.S., Motten, L.B., 1997. Linking restoration and landscape ecology Restor. Ecol. 5, 318-323.

Bender, D.J., Tischendorf, L., Fahrig, L., 2003. Using patch isolation metrics to predict animal movement in binary landscapes. Landsc. Ecol. 18 (1), 17-39.

Bortoleto, L.A., (Master Science Dissertation) 2014. Análise da dinâmica de fragmentos florestais: estudo de caso de Sorocaba-SP. São Paulo State University, Bauru, SP, Brazil, pp. 78.

Botequilha Leitão, A., Ahern, J., 2002. Applying landscape ecological concepts and metrics in sustainable landscape planning. Landsc. Urban Plan. 59, 65-93.

Cairns Jr., J., Heckman, J.R., 1996. Restoration ecology: the state of an emerging field. Annu. Rev. Energy Environ. 21, 167-189.

César, R.G., Brancalion, P.H.S., Rodrigues, R.R., Oliveira, A.M.S., Alves, M.C., 2013 Does crotalaria (Crotalaria breviflora) or pumpkin (Cucurbita moschata) interrow cultivation in restoration plantings control invasive grasses? Sci. Agric. 70, 268-273.

Chetkiewicz, C.L.B., St. Clair, C.C., Boyce, M.S., 2006. Corridors for conservation: integrating pattern and process. Annu. Rev. Ecol. Evol. Syst. 37, 317-342.

Cook, E.A., 2002. Landscape structure indices for assessing urban ecological networks. Landsc. Urban Plan. 58, 269-280.

Del Moral, R., Walker, L.R., Bakker, J.P., 1991. Insights gained from succession for the restoration of landscape structure and function. In: Walker, L.R., Walker, J., Hobbs, R.J. (Eds.), Linking Restoration and Ecological Succession. Springer, London, pp. 19-44 (Chapter II).

Didham, R.K., 2010. Ecological consequences of habitat fragmentation. In: Encyclopedia of Life Sciences. Wiley \& Sons.

Durigan, G., De Siqueira, M.F., Franco, G.A.D.C., Bridgewater, S., Ratter, J.A., 2003. The vegetation of priority areas for Cerrado conservation in São Paulo State, Brazil. Edinburgh J. Bot. 60, 217-241.

Eastman, J.R., 2012. IDRISI Selva. Clark University, Worcester (software).

EPA (United States Environmental Protection Agency), 2003. Forest fragmentation differentiating between human and natural causes. Fact sheet, p29. http://www. epa.gov/mrlc/pdf/forest-factsheet.pdf (accessed April 2015).

Ewers, R.M., Didham, R.K., 2007. The effect of fragment shape and species' sensitivity to habitat edges on animal population size. Conserv. Biol. 21, 926-936.

Fahrig, L., 2003. Effects of habitat fragmentation on biodiversity. Annu. Rev. Ecol. Evol. Syst. 34, 487-515.

FAO (Food and Agriculture Organization), 2000. Land Cover Classification System (LCCS), http://www.fao.org/docrep/003/x0596e/X0596e00.htm\#P-1_0 (accessed September 2014).

Farina, A., 2001. Landscapes and their ecological components. Living World 4, 435-448.

FIESP (Federation of the Industries of São Paulo State), 2013. Panorama da indústria de transformação brasileira, 2nd ed. São Paulo, SP, pp. 59.

Florentine, S.K., Westbrooke, M.E., 2004. Restoration on abandoned tropical pasturelands-do we know enough? J. Nat. Conserv. 12, 85-94.

Gibson, L., Lee, T.M., Koh, L.P., Brook, B.W., Gardner, T.A., Barlow, J., Peres, C.A et al., 2011. Primary forests are irreplaceable for sustaining tropical biodiversity. Nature 478, 378-381.

Gong, C., Yu, S., Joesting, H., Chen, J., 2013. Determining socioeconomic drivers of urban forest fragmentation with historical remote sensing images. Landsc. Urban Plan. 117, 57-65.

Gurrutxaga, M., Lozano, P.J., del Barrio, G., 2010. GIS-based approach for incorporating the connectivity of ecological networks into regional planning. J. Nat. Conserv. 18, 318-326.

Gustafson, E.J., 1998. Quantifying landscape spatial pattern: what is the state of the art? Ecosystems 1, 143-156.

Herold, M., Scepan, J., Clarke, K.C., 2002. The use of remote sensing and landscape metrics to describe structures and changes in urban land uses. Environ. Plan. A 34, 1443-1458.

Hill, J.L., Curran, P.J., 2003. Area, shape and isolation of tropical forest fragments: effects on tree species diversity and implications for conservation. J. Biogeogr. 30, 1391-1403.

Hilty, J.A., Lidicker Jr., W.Z., Merenlender, A., 2006. Corridor Ecology: the Science and Practice of Linking Landscapes for Biodiversity Conservation. Island Press, pp. 345.

Hobbs, R.J., Cramer, V.A., 2008. Restoration ecology: interventionist approaches for restoring and maintaining ecosystem function in the face of rapid environmenta change. Annu. Rev. Environ. Res. 33, 39-61.

Holl, K.D., Crone, E.E., Schultz, C.B., 2003. Landscape restoration: moving from generalities to methodologies. BioScience 53, 491-502.

IBGE (Brazilian Federal Institute for Geography and Statistics), 2012. Cid@ades - o Brasil município por município, www.ibge.gov.br (accessed October 2014).

IGSP (Geological Institute of São Paulo State), 2009. Geological Map of Sorocaba Municipality (report - in Portuguese)., pp. 59, Scale: 1:50,000.

Kepfer-Rojas, S., Schmidt, I.K., Ransijn, J., Riis-Nielsen, T., Verheyen, K., 2014. Distance to seed sources and land-use history affect forest development over a long-term heath land to forest succession. J. Veg. Sci. 25, 1493-1503.

Koch, I., et al., 2014. Plantas com flores e frutos das áreas de vegetação remanescente do Município de Sorocaba. In: Smith, W.S., Mota Jr., V.D., Carvalho, J.L. (Eds.), Biodiversidade do Município de Sorocaba. Municipal Secretary for Environment - Sorocaba, p. 270.

Kronka, F.J.N., et al., 2005. Inventário Florestal da Vegetação Natural do Estado de São Paulo. Secretaria do Meio Ambiente/Instituto Florestal. Imprensa Oficial, São Paulo, pp. 200.

Lambin, E.F., Geist, H.J., Lepers, E., 2003. Dynamics of land-use and land-cover change in tropical regions. Annu. Rev. Environ. Resour. 28, 205-241. 
Lapola, D.M., et al., 2014. Pervasive transition of the Brazilian land-use system. Nat. Clim. Change 4, 27-35.

Lausche, B., Farrier, M., Verschuuren, J., La Viña, A.G., Trouwborst, A., Born, C.-H., Aug, L., 2013. The legal aspects of connectivity conservation: a concept paper. In: IUCN Environmental Policy and Law Paper No. 85 Volume 1, Gland (Switzerland)., pp. 217.

Lillesand, T.M., et al., 2004. Remote Sensing and Image Interpretation. John Wiley \& Sons Ltd.

Lopes, C.G.R., Ferraz, E.M.N., Castro, C.C.D., Lima, E.N.D., Santos, J.M.F.F.D., Santos, D.M.D., Araújo, E.D.L., 2012. Forest succession and distance from preserved patches in the Brazilian semiarid region. Forest Ecol. Manage. 271, 115-123.

Murcia, C., 1995. Edge effects in fragmented forests: implications for conservation. Trends Ecol. Evol. 10 (2), 58-62.

Nathan, R., 2006. Long-distance dispersal of plants. Science 313, 786-788.

O’Neill, R.V., Hunsaker, C.T., Jones, K.B., Riitters, K.H., Wickham, J.D., Schwartz, P.M. Baillargeon, W.S., 1997. Monitoring environmental quality at the landscape scale. BioScience 47, 513-519.

de Oliveira, J.B., Camargo, M.N., Rossi, M., Calderano Filho, B., 1999. Mapa Pedológico do Estado de São Paulo. In: Legenda Expandida. Campinas: Instituto Agronômico; Rio de Janeiro: EMBRAPA-Solos, pp. 64.

Palmer, M., Bernhardt, E., Chornesky, E., Collins, S., Dobson, A., Duke, C., Gold, B., Jacobson, R., Kingsland, S., Kranz, R., Mappin, M., Martinez, M.L., Micheli, F., Morse, J., Pace, M., Pascual, M., Palumbi, S., Reichman, O.J., Simons, A., Townsend, A., Turner, M., 2004. Ecology for a crowded planet. Science 304, 1252-1253.

Patton, D.R., 1975. A diversity index for quantifying habitat "edge". Wildl. Soc. Bull. 3, 171-173.

Poyatos, R., Latron, J., Llorens, P., 2003. Land use and land cover change after agricultural abandonment: the case of a Mediterranean mountain area (Catalan Pre-Pyrenees). Mt. Res. Dev 23, 362-368.

Ranta, P., Blom, T.O.M., Niemela, J., Joensuu, E., Siitonen, M., 1998. The fragmented Atlantic rain forest of Brazil: size, shape and distribution of forest fragments. Biodivers. Conserv. 7, 385-403.

Renetzeder, C., Schindler, S., Peterseil, J., Prinz, M.A., Mücher, S., Wrbka, T., 2010. Can we measure ecological sustainability? Landscape pattern as an indicator for naturalness and land use intensity at regional, national and European level. Ecol. Indic. 10, 39-48.

Ribeiro, M.C., Metzger, J.P., Martensen, A.C., Ponzoni, F.J., Hirota, M.M., 2009. The Brazilian Atlantic Forest: how much is left, and how is the remaining forest distributed? Implications for conservation. Biol. Conserv. 142, 1141-1153.

Ries, L., Fletcher Jr., R.J., Battin, J., Sisk, T.D., 2004. Ecological responses to habitat edges: mechanisms, models, and variability explained. Annu. Rev. Ecol. Syst. 35 $491-522$.
Rodrigues, E., (Doctoral thesis) 1998. Edge effects on the regeneration of forest fragments in south Brazil. Harvard University Cambridge, Massachusetts, pp. 192.

Rodrigues, R.R., Lima, R.A., Gandolfi, S., Nave, A.G., 2009. On the restoration of high diversity forests: 30 years of experience in the Brazilian Atlantic Forest. Biol. Conserv. 142, 1242-1251.

Rudnick, D., Ryan, S.J., Beier, P., Cushman, S.A., Dieffenbach, F., Epps, C., Trombulack S.C., 2012. The role of landscape connectivity in planning and implementing conservation and restoration priorities. In: Issues in Ecology-Report number 16. Ecological Society of America.

Saadat, H., Adamowski, J., Bonnell, R., Sharifi, F., Namdar, M., Ale-Ebrahim, S., 2011. Land use and land cover classification over a large area in Iran based on single date analysis of satellite imagery. ISPRS J. Photogramm. 66, 608-619.

Schneiders, A., Van Daele, T., Van Landuyt, W., Van Reeth, W., 2012. Biodiversity and ecosystem services: complementary approaches for ecosystem management? Ecol. Indic. 21, 123-133.

Schumaker, N.H., 1996. Using landscape indices to predict habitat connectivity. Ecology $77,1210-1225$.

SEADE (Sao Paulo State's Secretary of Planning and Regional Development), 2012. Perfil Municipal, Available from http://www.seade.gov.br/produtos/ perfil/perfilMunEstado.php (accessed October 2013).

Shivanna, K.R., Tandon, R., 2014. Reproductive Ecology of Flowering Plants: A Manual. Springer, New Delhi, India.

Silva, A.M., Nalon, M.A., Kronka, F.J.D.N., Alvares, C.A., Camargo, P.B.D., Martinelli, L.A., 2007. Historical land-cover/use in different slope and riparian buffer zones in watersheds of the State of São Paulo, Brazil. Sci. Agric. 64, 325-335.

Silva, A.M., 2010. Land cover change and environmental quality assessment using GIS techniques - a case study in Brazilian Southeastern region for the period 1988-2003. Rev. Ambiente Água 5, 40-50.

Silveira, F.M., Silva, A.M., Ikematsu, P., Bomback, M., Paula, F.P., Nogueira, D.P., Alves, S.H., 2009. Variation of the occupied area by riparian zone according to considered width. Camin. Geogr. 10,111-119.

Smith, W.S., Mota Jr., V.D., Carvalho, J.L., 2014. Biodiversidade do Município de Sorocaba, 1 st ed. Municipal Secretary for Environment, pp. 270

Syrbe, R.U., Walz, U., 2012. Spatial indicators for the assessment of ecosystem services: providing, benefiting and connecting areas and landscape metrics. Ecol. Indic. $21,80-88$

Turner, M., 1989. Landscape ecology: the effects of patterns on processes. Annu. Rev Ecol. Syst. 20, 171-197.

Vittoz, P., Engler, R., 2007. Seed dispersal distances: a typology based on dispersal modes and plant traits. Bot. Helv. 117, 109-124. 